\title{
ENTREVISTA A LA DRA. ÚRSULA HAUSER INTERVIEW WITH DRA. ÚRSULA HAUSER
}

\author{
Entrevistadoras: \\ Marcela Ramírez Hernández* \\ Marcela Otárola Guevara**
}

\begin{abstract}
Resumen: Entrevista a la Dra. Úrsula Hauser, psicoanalista de amplia trayectoria en el trabajo con víctimas de conflictos armados. En su trabajo ha convergido el psicoanálisis y el psicodrama en aras de construir una memoria histórica a partir de los relatos de quienes se han visto afectados por hostilidades bélicas, para elaborar, así, otro que desafíe una narrativa hegemónica y conduzca, a la vez, a la formación de un proceso identitario que procure la justicia social.
\end{abstract}

Palabras claves: entrevista; psicodrama; memoria colectiva; psicoanálisis; historia; Úrsula Hauser.

\begin{abstract}
Interview with Ph.D. Úrsula Hauser, a long-standing psychoanalyst who has been treating victims of armed conflict. In her work she has converged psychoanalysis and psychodrama in order to build a historical memory from the stories of those who have been affected by war hostilities, to elaborate, thus, another that challenges a hegemonic narrative and procure, at the same time, the formation of an identity process that seeks social justice.
\end{abstract}

Keywords: Interview; Psychodrama; Collective Memory; Psychoanalysis; History; Úrsula Hauser.

Fecha de recepción: 01/01/2019 - Fecha de aceptación: 19/07/2019

Costarricense. Magister Scientae en Historia Aplicada por la Universidad Nacional (UNA), Costa Rica. Académica de la Escuela de Historia y del Instituto de Estudios Latinoamericanos (IDELA), ambos pertenecientes a la UNA, Costa Rica. Correo electrónico: mhr85@hotmail.com

** Costarricense. Magister Scientae en Historia Aplicada por la Universidad Nacional (UNA), Costa Rica. Académica de la Escuela de Historia de la UNA, Costa Rica, y doctoranda del Doctorado en Estudios de la Sociedad y la Cultura de la Universidad de Costa Rica (UCR), Costa Rica. Correo electrónico: zaida. otarola.guevara@una.ac.cr 


\section{Presentación ${ }^{1}$}

Ú

rsula Hauser nació en Zúrich, Suiza, en 1946. Es psicoanalista y psicodramatista, obtuvo su licenciatura en psicología en la Universidad de Zúrich (1974) y su doctorado en esa misma disciplina en la Universidad de Klagenfurt, Austria (1994). En la década de 1960 estuvo vinculada a movimientos políticos que evidenciaron un activismo que, hasta la fecha, la distingue como una internacionalista comprometida con la justicia social y la lucha en contra de la opresión, empeño que la ha llevado a trabajar con víctimas de la violencia en distintos lugares del mundo tales como Nicaragua, El Salvador, Costa Rica, Cuba, Guatemala, Uruguay, Chiapas y, desde hace 20 años, en Palestina.

$\mathrm{Su}$ quehacer profesional se ha abocado a establecer interacciones que eluciden las causas de la violencia social, objetivo que la condujo a emplear el psicodrama como un método para obtener historias de vida con las cuales, a partir del trato con individuos que fueron parte de conflagraciones políticas, elaborar una memoria histórica. Las premisas que permean su pensamiento señalan que, mediante el empleo del psicoanálisis, es posible vislumbrar el funcionamiento del poder, pero, es a través del psicodrama que el individuo puede expresarlas de una forma franca y sin inhibición; de esta manera, con los relatos obtenidos, es posible reconstruir una memoria colectiva que trastoca y desafía a otra establecida desde una posición de poder.

A continuación, se presenta un extracto de una amplia entrevista que se realizó en su cálida oficina en San José, Costa Rica; no obstante, de previo es necesario mencionar que, en sus más recientes reflexiones, la incorporación de la historia en sus investigaciones cobra una especial relevancia: ella contribuye a crear comunidades basadas en sólidos procesos identitarios, espacios en los cuales se promueve una praxis reflexiva en el ser humano y se evita la reproducción de vanas confrontaciones sociales:

\footnotetext{
"Muchas investigaciones internacionales e interdisciplinarias se han hecho, sin embargo, falta mencionar un punto importantísimo que supera el tratamiento psicológico y social: el de la recuperación de la MEMORIA COLECTIVA desde la visión de la generación de personas jóvenes. Solamente si ellas conocen su verdadera historia y pueden elaborarla subjetiva y colectivamente, pueden fortalecer su IDENTIDAD, y formar los conocimientos necesarios, que les ayuden a entender la historia familiar, de su barrio, su ciudad, su país. Esta es la base para formar la toma de posiciones ideológicas y políticas, para no reaccionar emocionalmente con rencor, resentimientos, confusión e indiferencia, que junto con otras reacciones profundizan la posible neurosis y la disfunción social".2
}

1 La transcripción de la entrevista fue realizada por Dalia Arce Aguirre.

2 Úrsula Hauser, "El Psicodrama en la construcción de la memoria histórica. Las huellas de la dictadura uruguaya en la tercera generación”, Giros de Aspas, 11 (noviembre, 2015), en: https://www.fundacionursulahauser.org/giros-de-aspas 
Revista de Historia (RH): Buenas tardes doña Úrsula, hemos preparado una serie de preguntas, para más que entrevistarla, dialogar con usted. Lo que nos interesa mucho es hablar sobre la construcción de la memoria histórica a través del psicoanálisis, también del psicodrama, y hacer acoplo de toda la experiencia que usted tiene en el nivel internacional trabajando con grupos de mujeres. Muchísimas gracias por el espacio.

Úrsula Hauser (UH): Más bien es un placer y además la UNA es para mí también como mi casa, siempre me encanta hacer allá conferencias de trabajo y ahora estar con ustedes, con uno de los temas principales que a mí me interesa, más bien es un placer de mi parte de poder, ojalá, dialogar de modo productivo y constructivo.

RH: Muchas gracias. Vamos a iniciar preguntándole, ¿cómo ha sido el proceso que le permitió a usted formarse como investigadora social y cómo determinó su ámbito de estudio?

UH: Soy de la generación del 68, en Europa. En Suiza me críe en una familia de clase media, tranquila, supuestamente en un país que, hasta hoy, dice que es democrático, neutral, aunque ni la neutralidad existe, ni todavía logramos una democracia que económicamente sería de justicia social e independiente de los grandes imperios; Suiza con los bancos suizos, obviamente no lo es.

Entonces, yo rompí o las circunstancias hicieron que yo rompiera el camino de ser maestra de primaria, me involucré en los movimientos políticos del 68 en Europa, que no fueron tan violentos como en Latinoamérica verdad: ya en los sesenta sabemos que en el Cono Sur y aquí también, había muchos movimientos políticos, sociales, pero yo, ahí, como estudiante de psicología, me involucré en los Comités de Solidaridad con Centroamérica: en específico El Salvador y Nicaragua. Esto fue paralelo, lo político, con mis estudios en psicología social en la Universidad de Zúrich y, me hice psicoanalista.

Como maestra, todavía, trabajé siempre para poder financiar mis estudios y, empecé a aplicar el psicoanálisis o los saberes del psicoanálisis a la pedagogía, eso se llama lo antiautoritario, es decir, cambiar el sujeto o influir en cómo se podrá cambiar la mentalidad. Como Vera Smith, por ejemplo, ella, creó en la Unión Soviética los jardines infantiles -kindergarden- antiautoritarios, aplicando el saber del psicoanálisis de la sexualidad infantil, que es muy importante no reprimirlo, no castigarlo, porque eso inhibe, diríamos, el desarrollo infantil. La neurosis, que sería desde la represión sexual, bloquea, censura la curiosidad y por lo tanto eso influye también en la adultez después como bloqueos de trabajo, 
por ejemplo, o bloqueos de estudiar; y eso diríamos, fue lo que me fascinó desde el inicio del psicoanálisis: es el saber desde lo propio, desde mi proceso, entre más miedo tengo, más vergüenza o más culpa, menos creativa puedo ser. Las inhibiciones tienen que ver con la represión sexual, esto es un saber psicoanalítico, que por eso el psicoanálisis nunca fue aceptado en las ciencias tradicionales porque choca contra la ideología de la Iglesia primero, del Estado burgués, de la pequeña familia hetero, ${ }^{3}$ que considera la homosexualidad como enfermedad, $o$ que dice eso es la norma y así sería la salud mental y, toda la neurosis que tenemos en todo lado, es de pequeñas familias hetero.

Entonces este pensamiento rebelde, antiautoritario, junto con mi politización de leer a Marx, y de entender que los pobres no son pobres porque no trabajan -como lamentablemente es un prejuicio todavía tan soberbio en Suiza- y de ver cómo Marx y Freud coinciden en algunos puntos; porque en aquel tiempo leímos muchísimo, nuestros días tenían como cuarenta horas: porque, aparte de trabajar como maestra y estudiar en la universidad, hicimos todo un trabajo político de militancia en los barrios. Esas fueron las influencias: por un lado, las de mi psicoanalista, después las de mi grupo en formación de psicoanálisis, que hicimos en el 69 un movimiento que se llama Plataforma Internacional ${ }^{4}$ que duró veinte años y que es la izquierda psicoanalítica internacional, fue del 69 hasta el 89 y agrupó en Suiza un grupo grande: había austriacos, alemanes, de Bretaña, de Italia sobre todo y, muchos de Argentina.

Ahí se hizo el primer puente para mí con Latinoamérica, vía colegas. Venían en exilio a Europa, y por eso tuvimos que aprender, por ejemplo, como se hace psicoterapia con lo militante político que es clandestino, o como se puede entender una paranoia que es un miedo real porque es perseguido, porque eso fue lejos de nuestra realidad en Suiza, también teníamos choques con la policía, pero nunca en un contexto clandestino de verdad. Ahí, con esa Plataforma Internacional, se unió la psicología con la política, que para mí es hasta ahora mi pasión, y siempre pensando desde el contexto cultural, el contexto histórico y social: dónde te criaste, en qué clase social, y por qué uno se metió, por ejemplo, a estudiar historia, a ser psicoanalista, y también por qué uno se mete en militancia política, eso no es por casualidad, sino esto es un hilo rojo en la propia historia.

Bueno, esto que teníamos de tu pregunta es lo que me llevó a este camino; siempre son también dolores, crisis, para no decir traumatismos. Gracias, en mi caso al psicoanálisis, yo pude día a día reflexionar, ver cómo es el psicoanálisis en el diván, que nadie te dice qué hacer, sino te ayudan a entender tu historia mejor y a ver lo que no quiero repetir de mi madre o mi abuela; y como estoy construyendo eso que llamamos identidad, o ese yo en un contexto tal.

3 La autora hace referencia al término heterosexual.

4 Organización de izquierda creada en 1969 que articuló una red de psicoanalistas europeos y latinoamericanos. 
RH: Ahora nos comentó un poco cómo a través de Plataforma Internacional se pudo vincular con algunos exiliados argentinos, y estoy segura que en el libro La rebelde 5 viene una reseña al respecto, pero nos podría comentar, ¿cómo fue que se vinculó usted con el contexto latinoamericano, lo que la hizo llegar de Europa hacia América Latina y, también, ¿qué la condujo a vincularse con la memoria histórica a través de militantes políticos?

UH: Siempre el amor también tiene su rol, muy importante ¿verdad? A parte de una, yo me imagino, nunca uno entiende todo su inconsciente, siempre nos acercamos a saber más, o a entender más de la propia historia, pero yo creo como yo vengo de una familia súper encerrada, muy autoritaria, un pueblo muy conservador, necesitaba como salir, ¿no?

También porque tenía una muy buena base, sobre todo desde mi madre. Una persona traumatizada, torturada, que sufrió en la niñez abandonos, desarrolla una identidad frágil, y yo me pude desarrollar desde una infancia, en ese sentido, muy segura, sin miedos o tragedias grandes. Tuve una confianza en mí que me permitió ser aventurera, de lanzarme, también hice deportes súper peligrosos. Ese espíritu de aventurera seguro influía en lo que es más lo intelectual y la fascinación de lo extraño, es decir, muy al revés de mi pueblo: en aquel tiempo los inmigrantes trabajadores fueron italianos y ahí ya se hicieron leyes fascistas, antinmigrantes, anti-italiano, después fueron los españoles, después los turcos, etcétera, pero lo xenofóbico es el miedo de las personas hacia lo extraño, estos vienen a sacarnos la tranquilidad, son sucios, todas esas proscripciones, a mí siempre me fascinaron.

Como dije, ya en la universidad, en el grupo de base, como le llamábamos de militancia, ahí había ya un conocimiento porque se hizo el Comité de Solidaridad con Centroamérica. Yo me metí, no conocía a nadie, yo me metí. Yo me recuerdo que hicimos acciones delante de los supermercados para concientizar a los obreros de que es un crimen los salarios de los trabajadores en las bananeras, en la United Fruit Company, eran una explotación, que no había que comprar bananos. Bueno, todo eso verdad, ya había un acercamiento vía los productos que comíamos y nosotros hemos dicho: "pero ahí hay muchísimo trabajo adentro y ni sabemos"... Entonces fue como una época quizás ilusoria, pero de concientizar.

Y el amor en mi caso fue con un argentino, un psicoanalista maravilloso que se llamó Armando Bauleo. Con él, en 1971, en la Plataforma hicimos un anticongreso en Viena de la IPA,${ }^{6}$ la Internacional Organización Psicoanalista

5 Tanja Polli, La rebelde (San José, Costa Rica: Editorial Arlequín, 2017).

6 Asociación Psicoanalítica Internacional conocida como IPA -International Psychoanalytical Associationpor sus siglas en inglés. Institución reguladora del psicoanálisis en el nivel mundial. 
[sic]: conservadora, jerárquica, patriarcal la figura de autoridad que no te dejan ser creativa, nuestro psicoanálisis no quiere adaptar a la persona a un sistema, al menos jerárquico.

Entonces, en 1971, en ese congreso se desafió a la IPA o la Organización Internacional de Psicoanálisis, que hasta hoy día es conservadora, y se hizo un anticongreso que tocó la noción de neutralidad, que hemos dicho no es posible, los psicoanalistas también somos ciudadanos, e interpretamos desde una posición ideológica. Los de la IPA han dicho que todos somos neutrales, la política no entra en nuestra ciencia. Entonces, ninguna ciencia es neutral, la historia tampoco, porque quien escribe la historia o la transmite se olvida de ciertas cosas y no es por casualidad. Es imposible [la neutralidad], somos seres sociales y culturales desde el inicio, hay que saber el contexto desde lo histórico-cultural.

Es decir, la sociedad, la estructura de la sociedad nunca es neutral, siempre desde la historia trae la parte de discriminación, de injusticia social consigo y esto lo aprendimos a analizar solo porque nos politizamos. Yo hice en el 74 mi licenciatura en la Universidad de Zúrich, de psicología social y el tema fue "Teorías de Socialización: un Enfoque Psicoanalítico y Marxista", eso solo lo pude hacer en el 74 por los movimientos sociales y colectivos; el marxismo mismo hoy día sería difícil en la Universidad de Zúrich hacerlo. Con el mismo profesor, después, quería hacer el doctorado en etno-psicoanálisis, entonces fui a Nicaragua, hice mi tesis sobre mujeres en camino, ${ }^{7}$ una investigación etno-psicoanalítica y él no lo aceptó. Cambié a la Universidad de Klagenfurt en Austria, que estaba especializada en etno-psicoanálisis, porque el etno-psicoanálisis, tampoco es neutral, porque surgió o nació con Goldy Parin-Matthèy, Paul Parin y Morgenthaler ${ }^{8}$ en Zúrich. También, ya había antecedentes con George Devereux, un francés que dijo que nunca en las ciencias antropológicas-sociales se puso la atención sobre quien investiga, siempre sobre el objeto de investigar: los blancos, europeos, o gringos, canadienses van a investigar a los negros, a los indígenas y nunca ni siquiera hablan de su motivación, y mucho menos, hablan después a quien sirve eso. Lejos de ser neutral, la mayor parte fue, lamentablemente, en el servicio de dominar mejor y explotar mejor estos pueblos colonizados.

RH: ¿Cómo incide toda esta posición que usted manifiesta en los pueblos latinoamericanos?, ¿cómo incide el etno-psicoanálisis, el psicodrama en los pueblos latinoamericanos desde esta posición, desde esta ruptura que

7 La Dra. Hauser se refiere a su tesis titulada, Mujeres en camino; vida de mujeres en cambios políticos. Un estudio etnopsicoanalítico con mujeres nicaragüenses durante 1981-1984, presentada en la Universidad de Klagenfurt, Austria, en 1994.

8 Goldy Parin-Matthèy, Paul Parin y Fritz Morgenthaler, equipo de psicoanalistas suizos que fundaron la Escuela del Etnopsicoanálisis, sitio donde enseñaron el método del etnopsiconálisis y que ha sido aplicado en múltiples investigaciones alrededor del mundo, particularmente en comunidades expuestas a conflictos armados o a la represión política y militar. 
ustedes hacen entre un psicoanálisis que se quiere hegemónico y tratando de generar una autonomía, motivando la ruptura de hegemonías en los pueblos latinoamericanos?

UH: Bueno, en mi caso, porque estoy aquí, porque en Suiza tendría una vida súper cómoda y tendría hasta casita, pero yo me fui a Nicaragua consecuente con mi pensar, porque yo cuando estaba ya muy informada por el Comité de Solidaridad con Centroamérica, sabíamos de todas las organizaciones revolucionarias acá y cuando fue el triunfo de la revolución en el 79 yo dije: ahí tengo que ir, y me fui, todo en autofinanciación, yo no fui rica pero tenía en Suiza un ahorrito para una visita a Nicaragua.

¿Cómo organizar el poder para que no se repita la vieja estructura? Quería hacerlo y por eso, en Semana Santa del 81 me fui, supuestamente por dos años. Yo vivía ahí en un barrio, trabajé con las mujeres costureras, aprendí muchísimo de ellas, hice una investigación etno-psicoanalítica y los domingos psicodrama, porque fue claro el alcoholismo, por ejemplo, de los hombres y por lo tanto, la violencia doméstica contra mujeres y niños fue número uno en estos barrios y ahí también los hombres se comprometían en sesiones de psicodrama para ver cómo se podría cambiar.

$\mathrm{Y}$ ahora les explico por qué vine yo al psicodrama. Esto fue a inicios de 1970, ya yo estaba en psicoanálisis ortodoxo, trabajé en barrios proletarios como maestra. Y el teatro siempre me gustó, eso también fue una entrada, gané también dinero iluminando un teatro en aquel tiempo, a inicio de los $70, \mathrm{y}$ todo eso me fascinó, de hecho, si no me hubiera hecho psicoanalista sería dramaturga.

En el psicodrama pude sintetizar ambas cosas, porque vi que hay que involucrar el cuerpo. Yo dije: si yo soy europea y soy etno-psicoanalista, entonces siempre piensan que yo soy blanca, mujer, clase media; que atrás mío está Cortés ${ }^{9}$ y es la conquista europea. Todo eso influye en el inconsciente colectivo: si yo trabajo en Chiapas con zapatistas, o trabajo en Palestina con otras culturas que fueron colonizadas por europeos; si yo no tengo este contexto en mi mente, reacciono subjetivamente cuando alguien me desafía. Entonces, en el psicodrama se da este lugar, por ejemplo, la silla vacía: si veo que hay alguien que siempre me mira así, con desconfianza, meto la silla ahí, me levanto y digo: "mirá aquí soy yo, esto es Úrsula, ¿quién más está ahí?”, enseguida viene el colonizador y digo: ¡fenomenal que desconfían de quién soy yo!, si uno tematiza eso ya gana la confianza; pero casi nadie tematiza, al contrario, algunas y algunos izquerdistas se pueden sentir insultados.

En Nicaragua, en el tiempo que el Instituto Lingüístico mandó tanta gente a "ayudar" a los sandinistas desde Miami, fueron la mayor parte gente de la CIA,

9 Se alude a Hernán Cortés (1485-1547), el conquistador español. 
eso fue a final de 81 , inicio de 82 . Los sandinistas tenían que hacer un filtro de todos estos internacionalistas: ¿quiénes son de verdad solidarios?; yo aplaudí eso mientras muchos de mis colegas, inclusive suizos, decían: "que increíble, ahora venimos, hacemos sacrificios, comemos arroz y frijoles y vivimos ahí". Pero tenemos que entender una duda: mire estos lingüistas, los otros antropólogos, y psicólogos, ¿para qué o para quién están trabajando?

Bueno, así que el contexto en Latinoamérica, en el encuentro con alguien como yo -y que hay muchos- el trabajo de uno es de muchísimo apoyo para fortalecer la identidad cultural de estos otros pueblos cuando se tematiza no admirar lo blanco. Esa identificación con el agresor, que es solo posible si se olvida la memoria, se puede apoyar muchísimo sobre la conciencia de la memoria, la cultura, ¿verdad? y en una u otra forma, ¿cómo rechazar lo que se da automáticamente? Lamentablemente hay pueblos dominados que idealizan al blanco, que idealizan al poder. Entonces nosotros tratamos de dar [hacer] lo pequeñito, un antimovimiento. Muchas veces también dice la gente: "claro, ay tú sos suiza, que lindo todo allá", y digo: "si, es lindo, y aquí ustedes ¿por qué admiran tanto lo que fue su opresión y que sigue chupando de donde viene el oro, el café? Todo viene de acá, es concientización política.

Y el psicodrama va con el cuerpo. Acá, y en muchísimos países, la mitad de la Caja ${ }^{10} \mathrm{o}$ de los hospitales están llenos de pacientes psicosomáticos; la causa es emocional, está en la historia de uno, puede ser transgeneracional: lo que vivió la abuela como esclava real o esclava mental siempre diríamos sumisa, siempre culpable. Alienado de su cuerpo, alienado de sus derechos, esto trabajamos. Por ejemplo, el psicodrama en el cuerpo ¿de dónde viene tu síntoma? Una vez piensa [sic] ¿cuándo empezó? ¿En qué contexto histórico produjiste este síntoma? y desaparecen los síntomas, porque si puedes deconstruir lo que se hizo en cierto contexto, expones un síntoma en el cuerpo para expresar el dolor, porque la persona no está consciente de su historia, y de esto muchísimo es la rabia; por lo tanto, yo utilizo en el psicodrama lo que aprendí.

En el psicodrama veo personas que, por alguna razón, no solo lo económico, nunca irían a una terapia para hablar en un grupo de la misma cultura. Al inicio tampoco quieren hablar, pero el psicodrama trabaja con el cambio de rol, el psicodrama es el corazón de meterse en los zapatos de la otra persona y si hay, como siempre, diferentes niveles de poder. Algo que atraviesa el cuerpo y el inconsciente se manifiesta de otra manera: el hablar, al final es siempre el hablar.

Una anécdota desde los años de 1970, en Suiza, en este primer grupo que hice con mujeres, había una mujer que fue hija de campesinos en Suiza, y nunca habló; de hecho, un psiquiatra me la refirió y decía: "Yo no sé qué hacer con esa mujer, no habla y escuché que usted hace esa cosa de teatro". Tampoco habló conmigo o en

10 La entrevistada se refiere a la Caja Costarricense de Seguro Social (CCSS), institución autónoma encargada de la seguridad social en Costa Rica. 
el grupo, hasta que en algún momento le propongo que ponga en acción su finca, donde ella vivía, entonces dijo: "Sí, sí, sí, yo quiero mostrarles como vivo" Le digo: ¿y tú. que quieres ser?, entonces dice: "yo quiero ser la vaca líder".

En Suiza todas las vacas tienen nombres: Lisi, Marie, etc., ella dijo: "Yo quiero ser la vaca Lisi, la líder de las vacas". Como es una manada, cuando van a los Alpes va al frente de todos y tiene a cargo la campana -se refiere a la líder-. Y esta mujer, que nunca fue activa -comúnmente-, que nunca se movió, empezó en el rol de la vaca, de la Lisi, y de repente fue alegre, empezó a moverse; ¡no lo podíamos creer! Hicimos toda una escena hasta que ella dijo: "ahora viene Vati -mi papá- a ordeñarme" y en seguida yo sabía de qué se trataba... ella lo dijo así, inconscientemente y tocó el tema del incesto.

Esto nunca hubiera aparecido de tú a tú, así le cayó, como decimos, el cinco o el veinte y empezó a llorar, llorar, llorar, y ahí fue fácil para mí decir: cuéntenos que está pasando y contó el incesto de su padre hacia ella, desde los 12 años. Eso fue algo que me convenció que, con cierta población, en ciertas condiciones culturales, sociales e históricas, se puede con psicodrama liberar la persona de su represión interna porque en el sujeto hay una necesidad de hablar de la verdad. La verdad no se olvida, se reprime, pero no se olvida.

RH: Cambiando la línea de lo que nos viene comentando ahora: estudiando su trayectoria ha estado en otros países, como por ejemplo en Uruguay y Argentina trabajando con víctimas del terrorismo de Estado. ¿Qué significó entonces, desempeñarse desde el psicodrama y el psicoanálisis en este contexto donde se necesitaban la confianza por parte de estos sujetos y en el que a la vez, habia una serie de politicas de estado que obligaban a los silencios, al olvido?

UH: En Costa Rica empecé desde 1991 con grupos de psicodrama y formación, pero en el contexto de traumatismo de guerra fue con el grupo de Mélida Anaya Montes ${ }^{11}$ de El Salvador que por lo menos de lo que yo conozco, fue la primera organización de izquierda revolucionaria en darse cuenta que necesitaban de terapia, de psicodrama o de una forma posible, para trabajar sus traumatismos de guerra y como mujeres, el tema de la violación. Siempre la tortura sexual va hacia las mujeres, primero; segundo, por haber sido rechazadas por sus propias familias y su comunidad por "malas madres”: “¿cómo va con un fusil a la montaña, en lugar de estar con su familia?". Es decir, la culpa tremenda también desde la Iglesia en un contexto muy católico.

11 Más conocido como "Las Mélidas", la Asociación Movimiento de Mujeres Mélida Anaya Montes, es una agrupación feminista salvadoreña surgida en 1992, dedicada a la lucha por el derecho a la participación política de las mujeres, al autocuidado, denuncia de la violencia y capacitación profesional. Consultado en: https://www.lasmelidas.org.sv/index.php/historia 
En el FMLN, en las cúpulas de hombres, no se habla de la tragedia de las muertes de los "padres de la organización", solamente las MELIDAS tomaron el nombre de la comandante Ana María, nombre civil de Mélida Anaya Montes, una maestra que fue lideresa en el FMLN, en la guerrilla, y que tiene una historia que sigue siendo tabú en muchos de los ámbitos de liderazgo de izquierda, por la ansiedad de PODER. Gayetano Carpio [sic] fue otro líder; ellos fueron las figuras de madre y padre en el FMLN de los 80. Ella tenía una fuerte mística con la gente, es decir, la querían muchísimo; se ha asumido que Carpio la dejó matar y ¡después se suicida! Sin embargo, dado al SILENCIO, „no se sabe la verdad! Esta tragedia, ese femicidio, motivó a la organización feminista "Mélidas" a darse el nombre de la comandante Ana María, para no olvidarla y trabajar la problemática del PODER y la RIVALIDAD de hombres hacia mujeres desde el psicodrama.

Igual en Uruguay y por el terrorismo de Estado, es muy importante de trabajar los traumatismos de la guerra. Pues fíjate yo tuve un sueño hace como 6 o 7 años, y en ese sueño -yo doy mucha importancia a los sueños, soy psicoanalistaapareció mi pareja Antonio, quien murió en el año 1996. Estaba en un bote listo para bucear, yo estaba lista para dejarme caer cuando él viene y me pregunta: ¿cómo va tu investigación? En el sueño yo sabía de qué habla: las huellas de la dictadura en la tercera generación. Le dije: Sí, va bien, pero qué me aconsejas, ¿trabajo solo con nietos de la izquierda o también del otro lado, de los militares? Y me dice: "Lo más amplio posible" y ahí me desperté.

Empecé a escribir el proyecto que durante 5 años realicé. En esos seminarios con los nietos un chico me preguntó lo mismo cuando le pedí organizar el grupo con sus amigos: “¿y qué solo los nuestros o también del otro lado?”, ${ }^{12}$ pero me dice: "Yo no podría escuchar a otro que habla de su abuelo y que este, quizás torturó a mi abuelo, mejor lo hacemos en dos grupos". Tuvimos la coincidencia que en uno de los grupos estaba una chica que trabajó en derechos humanos en la Municipalidad de Maldonado -Uruguay-. En el psicodrama sale la verdad: en un diálogo surrealista yo dije: "¿con quién quisieran hablar algo de su historia?" Ella escogió a su padre y hacemos un diálogo surrealista, y de repente tiene una catarsis tremenda, llora, y dice a este padre: “¿cómo has podido ser milico y nunca me contaste?" Esa chica nunca lo trabajó en derechos humanos, nadie sabía que era hija de un militar retirado. Un año después, cuando hago un seguimiento ella contó: "Empecé a investigar, mi madre no habla, mi padre tampoco, pero un tío me dijo que mi padre estuvo involucrado cuando torturaron hasta la muerte a Eduardo Mondello en Piriápolis". ${ }^{13}$ De esto le mostré una película, un

12 La entrevistada se refiere a introducir en los seminarios de psicodrama tanto a los nietos de militantes de izquierda y a los nietos de los militares.

13 Eduardo Mondello Techera fue un uruguayo, casado, padre de dos hijos y fotógrafo de profesión. Militante del Movimiento de Liberación Nacional-Tupamarus (MLN-T) fue detenido por agentes encubiertos de la policía estatal del Uruguay el 6 de marzo de 1976 en Lavalleja. Durante su detención, fue torturado hasta la muerte. Desde el 2017, se investiga a nueve hombres como los presuntos torturadores de Mondello. El 
testimonio, y su padre fue uno de los torturadores; eso ella lo tenía que descubrir a raíz de ese trabajo.

Es decir, eso no es coincidencia, lo fuerte y útil que es el psicodrama en este caso de terrorismo de estado, que tocó a la mayor parte de los abuelos y abuelas de quienes ahora están entre los veinte y los treinta años. Un tema que nunca se pudo hablar, primero porque durante la dictadura eran innombrables los tupamaros, era una amenaza de muerte, es decir, había miedo real y luego, ya la mayor parte - de la gente- no quería hablar. Esta es la parte del pacto de silencio entre quienes fueron las víctimas y no querían hablar por proteger a los hijos, lo que es un gran error, pero es entendible. No querían que los hijos o hijas supieran cuánto han sufrido y los hijos e hijas no quieren preguntar: eso aprendí en aquel contexto, porque no quieren recordar un tiempo de tanto dolor y de tanto miedo.

Entonces, con el interés político en las llamadas democracias después de las dictaduras, se puso punto final: olvidemos todo, empecemos de nuevo, consumismo y lo que antes dijimos, el imperialismo cultural. En Uruguay un símbolo de los más horribles es Punta Carretas ${ }^{14}$ una de las más horribles prisiones ahora es un supermercado [sic] y cada celda es una tienda, una boutique. Hablan de la alienación, de querer olvidar, de evitar que los jóvenes sepan la verdad.

RH: Esto nos lleva a una pregunta ¿Cómo estas memorias oprimidas, que tal vez son disidentes se enfrentan a estas memorias oficiales o hegemónicas? ¿cómo se enfrentan a estas borraduras que hacen también las dictaduras? Y la otra pregunta la riqueza del proceso del psicodrama, ¿cómo se sistematizan todas estas experiencias para generar una praxis dentro de los pueblos o de los grupos que han estado sojuzgados, en la búsqueda por revertir las historias oficiales? ¿Cómo se logra esa sistematización?

UH: Primero tenemos que ver que somos una minoría, hay muchísimos psicodramatistas $[$ sic], pero no todos son izquierdistas o incluyen su posición ideológica en su trabajo. En Uruguay, gracias a que se dio el vuelco histórico,

caso está a cargo de la Fiscalía Especializada en Derechos Humanos. En: Subrayado, "Crimen del fotógrafo Eduardo Mondello, torturado en dictadura, no prescribió", 29 de diciembre 2017, en: https://www. subrayado.com.uy/crimen-del-fotografo-eduardo-mondello-torturado-dictadura-no-prescribio-n73667; Gobierno de Uruguay, Secretaría de Derechos Humanos, Mondello Techera, Eduardo, disponible en: https://www.gub.uy/secretaria-derechos-humanos-pasado-reciente/sites/secretaria-derechos-humanos-pasado-reciente/files/documentos/publicaciones/MONDELLO\%20TECHERA\%2C\%20Eduardo.pdf

14 La Penitenciaria de Punta Carretas, fue un reclusorio de alta seguridad inaugurado en 1915 y clausurado por el gobierno en 1986. Posteriormente, el inmueble modificado albergaría el Punta Carretas Shopping Center creado en 1994. Durante la dictadura cívico militar (1973-1985) el centro penitenciario fungió como campo de concentración de presos políticos, principalmente, militantes del MLN-T que fueron ilegalmente privados de su libertad, torturados y asesinados. En: Conclusión, "De cárcel a shopping: la historia del centro comercial de Punta Carretas", 21 de noviembre 2017, en: https://www.conclusion.com. ar/info-general/de-carcel-a-shopping-la-historia-del-centro-comercial-de-punta-carretas/11/2017/ 
con los TUPAMAROS elegidos en el gobierno, con Pepe Mujica como presidente, con ministros tupamaros, se trabaja mucho en este asunto. Por ejemplo, el 27 de junio es la marcha del silencio, para los y las desaparecidas, medio millón de personas en la calle de un pueblito de apenas 5 millones. Es decir, hay un movimiento, esa es la esperanza del pueblo, jla de no olvidar a cada uno de los todavía desaparecidos en Uruguay!

En las universidades pienso que es súper complicado por diferentes razones hacerlo -el psicodrama-. Ahora lo que se puede hacer es a nivel privado, porque allá también muchos, muchas - psicoanalistas- se pensionan y viene un vacío en esta generación, de quienes fueron durante el terrorismo de estado, niños o jóvenes y no tienen la información o la formación política ni profesional. En la Facultad de Psicología de la UDELAR ${ }^{15}$ durante la dictadura había un carnicero que fue profesor, eran los amigos y amigas de los militares y sacaron a todos los subversivos de este psicoanálisis comprometido. Todos nuestros compañeros de la Plataforma estaban en el exilio y los y las estudiantes que se criaron y se formaron en aquellos 15 años oscuros, ¡no han podido pensar libremente y buscar las causas de la situación política! Las y los profesionales que volvían, ya tenían 60 años o 50 años; ¡esos ya rápido se pensionaron y muchos también tenían este desencanto de ver el tremendo trabajo que había que empezar a hacer desde cero en la facultad y a motivar a los jóvenes para el psicoanálisis y el pensar críticamente! Es decir, el enemigo logró una gran parte también a ese nivel. A otro nivel diríamos, como de los movimientos sociales o ese de los familiares de desaparecidos y de derechos humanos, a nivel privado se hacen cosas, pero no en la formación, que es tan importante, porque solo si se forma a la gente joven, el saber puede multiplicarse.

Logramos, gracias al Ministro del Interior y su asesora en el gobierno de izquierda en Uruguay, que el psicodrama se integrara en la Academia de policía, en la Guardia Republicana y en el sistema penitenciario; así, tratamos de apoyar en humanizar al personal del Ministerio del Interior. Esto es un proyecto pionero en América Latina y tiene mucho éxito, ¡lo que me hace feliz!En Guatemala ahora tenemos mucha esperanza de multiplicación, hay un grupo de 15 colegas, es interdisciplinario, hay algunos exguerrilleros muy comprometidos con el trabajo en derechos humanos y en memoria histórica y ahora laboran con grupos. Algunos círculos políticos han entendido que tienen que reelaborar las torturas que han sufrido, es decir, tienen que aceptar que nadie que va a la cárcel y es torturado, después de salir, es igual a como entró: por supuesto la persona tiene huellas. El gran problema es qué hacer con la violencia que se ha interiorizado, porque si te pegan o te hacen cosas horribles, algo se queda. La propuesta es de

15 Universidad de la República. Es la universidad estatal más grande de Uruguay y fue fundada en 1849. 
aplicar una psicología comprometida, el grupo operativo o el psicodrama sirve para cuestionar la relación del Poder con el sujeto y al Yo con el ROL asumido.

RH: Y ahora que menciona sobre las necesidades de intercambio, una de las cosas que nos llamó la atención dentro de sus ensayos era la relación del paciente, el terapeuta, de la transferencia y la contra transferencia. Desde la historia es muy importante entrar en diálogo con las personas cuando queremos hacer reconstrucciones, y algo que tratamos es no emitir valoraciones sino trabajar de la manera más objetiva, pero en estos procesos donde se trabaja con víctimas y victimarios o personas involucradas en conflictos tan dolorosos, ¿cómo se logra que esa relación profesional se mantenga, que no haya interferencias emocionales para poder elaborar una narración sobre la memoria?

UH: Por ejemplo, en Uruguay y en Argentina, había un gran grupo de psicoanalistas que les tocó vivir el terrorismo de estado y ahora de vuelta, atienden a otras víctimas del terrorismo de estado. En nuestro trabajo existe el requisito de hacer supervisión, pues siempre necesitamos hablar con otros colegas o poder llorar, pues uno nunca es invulnerable al dolor ajeno, sino seríamos tecnócratas. Pero, ¿qué hacer con nuestro dolor, nuestra rabia? no lo podemos sobrecargar al paciente o al grupo, sino que tenemos que controlar lo propio, nuestra interpretación dice algo desde nuestro lugar, retomo lo del inicio: actuamos o interpretamos, pero necesitamos al otro, el autocuidado y eso es poder hablar con otros colegas. Por eso, es recomendable, claro, siempre en confianza, pero que haya contra transferencia, pues la propia subjetividad se mueve permanentemente.

RH: ¿Usted cree que es posible articular una historia contra hegemónica a partir de las resistencias y de los silencios forzados?

UH: Por supuesto, no solo es posible, se hace. ¿Qué hacen los zapatistas?, ¿qué hacen -hablando de una de las poblaciones que tienen más fuerza de resistencia- los pueblos mayas que no se articulan tan públicamente como los zapatistas, pero están organizados, están en resistencia y saben que sí lograron resistir más de 500 años desde la conquista y luego a la feroz represión desde los años ochenta hasta ahora? Ellos y ellas lo viven desde lo histórico a largo plazo, gracias a su identidad cultural y su consciencia. En Palestina también, es increíble la fuerza de resistencia, la esperanza para que haya un cambio y donde hay una fuerza de resistencia fuerte en las mujeres.

Trabajamos con ASTRADOMES (Asociación de Trabajadoras Domésticas y Emigrantes Nicaragüenses) desde el 2013 con psicodrama y el apoyo de la Embajada de Suiza, con temas como la emigración y la opresión, motivando la 
denuncia de los abusos y otros temas. Trabajamos, ahora, desde la organización de psicodrama y teatro espontáneo en una intervención institucional desde la que se ha logrado colocar a 15 mujeres como las nuevas lideresas capacitadas desde esta organización junto con el INAMU.

RH: Quisiéramos aprovechar para darle un espacio para que usted dé un mensaje a nuestros lectores de la revista que, básicamente, son académicos y académicas quienes, a veces, están muy sumidos en el trabajo de la reflexión y no tanto en contacto con grupos en la sociedad. Entonces, ¿qué mensaje le daría usted a todos los que estamos en la academia?

UH: Quiero humildemente desde mi experiencia en muchos países y muchos ámbitos, darles fuerza para seguir adelante, no perder el hilo con su pueblo, no estar en la torre de marfil y hacerse elitista; aunque quizás no lo quieren ser, puede ser inconsciente. Somos privilegiados los académicos o intelectuales, pero eso es una responsabilidad y para mí es un deber devolver a la gente lo que aprendemos de ellas y de ellos y denunciar injusticias, abusos y no, cómodamente, callarse la boca y decir: "Mejor no me meto".

Esto sería mi mensaje: ¡HABLAR, no callarse, y COMPROMETERSE en proyectos y estudios no como un deber, sino dejarse fascinar en la dinámica con el afuera de la academia, con la comunidad, con lo extraño y también desde adentro de la $\mathrm{U}$ y con otras y otros estudiantes! Escuchar con curiosidad e interés, para poder dar y recibir, y VIVIR y no caer en una rutina o una subordinación, jeso es horrible! Buscar el placer, superar el egocentrismo y trabajar COLECTIVAMENTE. Podría ser lo que decimos desde el psicoanálisis: donde no hay Eros, hay Tánatos: la muerte.

¡Gracias! San José, Costa Rica

Marzo de 2019 